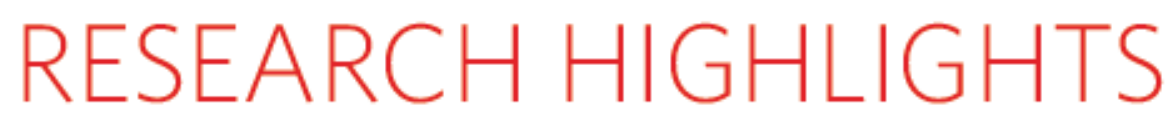

\title{
Singing in the rainforest
}

Proc. R Soc. Lond. B dot:10.1098/rspb. 2005.3410 (2006)

What deter mines when each bird species joins the dawn chorus? To find out, Karl Berg of Florida International University in Miami and his colleagues spent a month recording songbirds in the tropical forests of lowland Ecuador, home to species such as theocellated antbird (Phoenostictus mcleannani, pictured).

The researchers collected data on 57 species. Thesongbirds join the chorus in a chronological sequence determined by the height at which they roost in the 20-25metre-tall forest, and by the size of their eyes. This fits with the hypothesis that birds start to sing when conditions are bright enough for them to spot predators drawn by the noise, continuing until the light allows them to find food themselves.

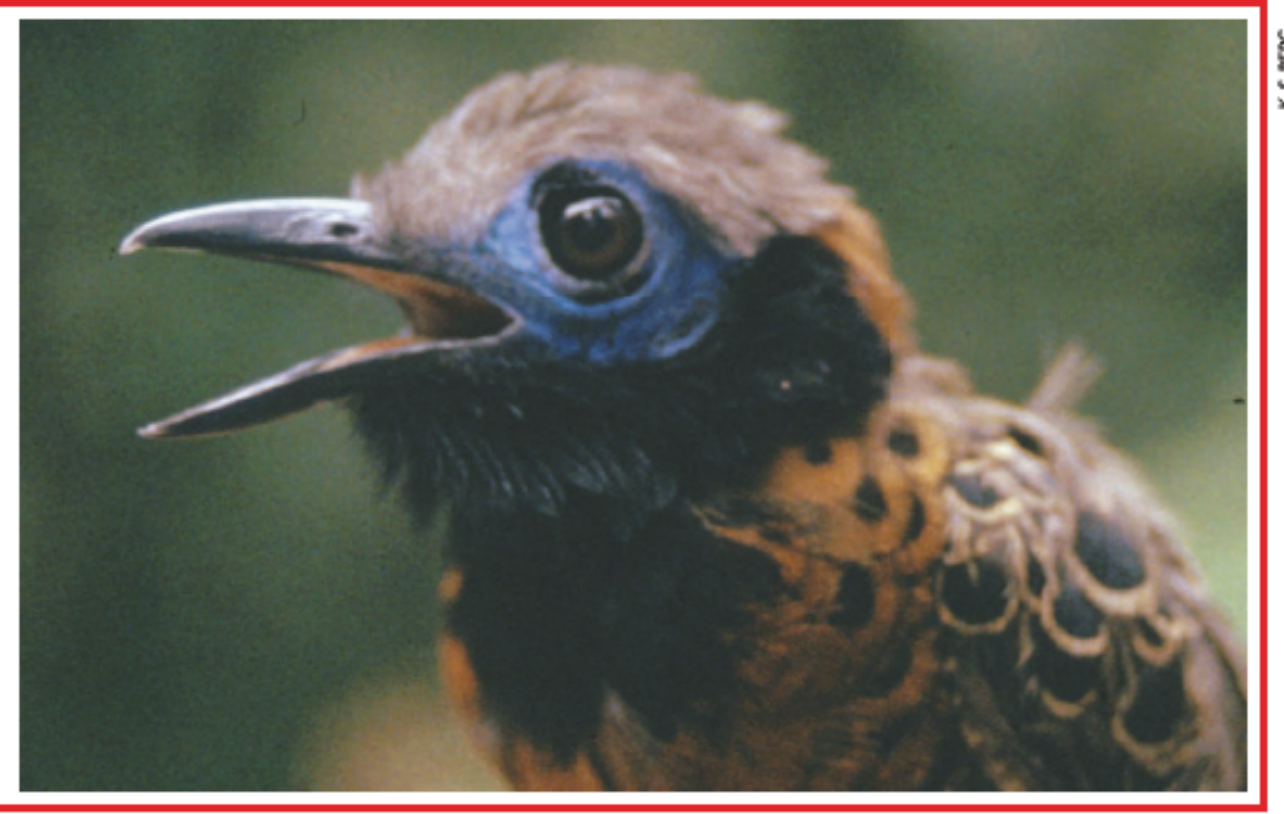

\section{CONDENSED MATTER}

\section{Highs and lows}

Phys. Rev. Lett. 96,017006 (2006)

For decades, physicists have been trying to convert pure hydrogen into a metal by compressing it. Theory predicts that this feat should be possible. However, despite reaching pressures exceeding 300 gigapascals - about 3 million atmospheres - they have failed.

Now Roald Hoffmann of Cornell University in New York and five other theorists have explored an alternative approach, which involves compressing molecules that contain hydrogen, such as silane $\left(\mathrm{SiH}_{4}\right)$.

They analysed 13 possible crystal structures for solid $\mathrm{SiH}_{4}$, concluding that it should become a superconducting metal at experimentally accessible pressures, possibly as low as 91 gigapascals.

\section{CELL BIOLOGY}

\section{Into your arms}

\section{J. Cell Sci. 119,370-379(2006)}

A moving amoeba may help researchers to uncover the function of a gene that is mutated in a rare human disease.

Patients with Shwachman-BodianDiamond syndrome (SBDS) can suffer problems with their immune system. It has also been observed that patients' white blood cells do not manoeuvre normally in response to chemical signals.

David Soll of the University of Iowa in Iowa City and his team identify the homologue of the SBDS gene in the amoeba Dictyostelium discoideum, and show that the protein it makes travels into the organism's protruding arms when it migrates in a chemical gradient.

The protein may carry RNA molecules required for cell movement, they speculate, and failure of this process might underlie some symptoms of the human disease.

\section{BACTERIOLOGY}

\section{Magnetic reversal}

Science 311, 371-374 (2006)

Some bacteria have internal compasses, made from a chain of magnetic iron crystals. Until now, everyone thought that Northern-

Hemisphere bacteria used their compasses to swim north, and Southern-Hemisphere bacteria used theirs to swim south. In either half of the globe, this would allow the bacteria to squirm into the lower-oxygen depths of water bodies by following the downward slope of the Earth's magnetic field.

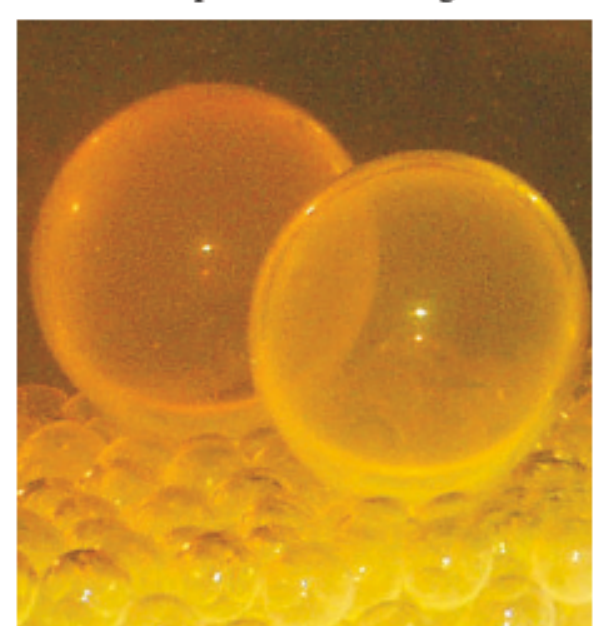

But Katrina Edwards of the Woods Hole Oceanographic Institution and two colleagues have smashed this simple explanation with the discovery of dumbbellshaped bacteria that flout convention. The iconoclasts, collected from a saltwater basin in the Northern Hemisphere, swim resolutely south under the microscope. The next thing to do is find out why.

\section{FLUID DYNAMICS}

\section{Not a drop}

Langmuir 22, 522-523 (2006)

Behold the antidrop! The two large bubbles in the picture (left) constitute a thin shell of salty water, sitting in and enclosing a mixture of oil and emulsifier. They are about eight millimetres across and rest on a bed of ordinary water droplets.

Discovered accidentally by a team of scientists in the United Kingdom and Australia, the antidrops are not to be confused with 'antibubbles', which are spherical films of air in water. The team, led by Kevin Galvin of the University of Newcastle, New South Wales, produced the antidrops by introducing oil though a perforated plate at the bottom of a vessel - the oil acquires an aqueous shell as it rises through the water drops.

\section{RNA INT ERFERENCE}

\section{Silent advance}

Genes Dev. 20,147-152 (2006)

'Inhibitory RNAs', a recently discovered class of RNA, have huge potential as tools in biology and medicine because they can 
inhibit the expression of specific genes.

Miles Wilkinson from the MD Anderson

W. Cancer Center in Houston, Texas, and his

$\mathrm{E}$ colleagues have developed a method of RNA

interference analysis that allows a specific

gene to be suppressed in just one tissue in

transgenic mice. Their trick exploits the way

5 that naturally occurring gene-suppressing

\&icroRNAs are produced.

They applied the technique to demonstrate that Wilm's Tumour 1 transcription factor, known to be required for normal development of mouse embryos, also plays an essential role in sperm production and motility in adult mice.

\section{MALARIA}

\section{Once bitten}

Nature Med, doi:10.1038/nm 1350 (2006)

Mosquito bites introduce the malaria-causing Plasmodium parasite deep into the skin. A study in mice has mapped its subsequent path.

Robert Ménard of the Pasteur Institute in Paris, France, and his colleagues tracked the fate of the rodent-infecting Plasmodium berghei, modified to express green

fluorescent protein.

Their real-time analysis reveals that, within an hour of a bite by an infected mosquito, roughly $50 \%$ of the cells injected into the mouse, known as sporozoites, have left the skin. Of these, about $70 \%$ enter blood capillaries and thus can lead to disease, whereas $30 \%$ go into lymphatic vessels.

The next two findings both came as a surprise. Most of the sporozoites entering the lymph system were degraded in lymph nodes. Also, some of the sporozoites in the lymph matured to a stage at which they could influence the immune response to the infection.

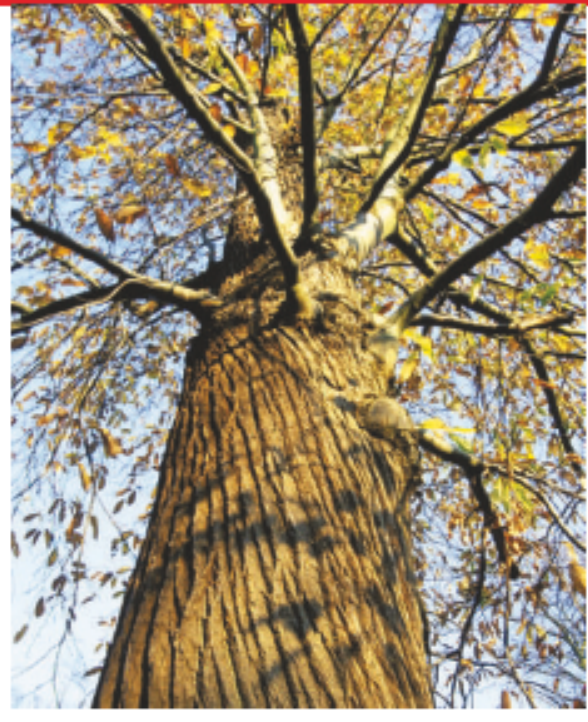

MATERIALS SCIENCE

\section{The complete Plato}

Small doi: 10.1002/smll.200500362(2006)

According to Plato, the heavenly ether and the classical elements - earth, air, fire and water - were composed of atoms shaped like polyhedra whose faces are identical, regular polygons. Such shapes are now known as the Platonic solids, of which there are five: the tetrahedron, cube, octahedron, icosahedron and dodecahedron. Microscopic clusters of atoms have already been identified with all of these shapes except the last.

Now, researchers led by José Luis Rodriguez-López of the Institute for Scientific and Technological Research of San Luis Potosí in Mexico and Miguel JoséYacamán of the University of Texas, Austin, complete the set. They find that clusters of a gold-palladium alloy about two nanometres across can adopt a dodecahedral shape.

\section{GENETICS}

\section{Two trees, side by side}

Genetics doi:10.1534/genetics.105.048439 (2006)

Comparing the genomes of oak and chestnut trees outlines the story of their evolution since the two species split 60 million years aga.
Antoine Kremer of the French Institute for Agricultural Research near Bordeaux and his colleagues have sequenced and compared DNA from oak (Quercus robur) and chestnut (Castanea sativa, pictured left). They looked at sites called quantitative trait loci (QTL), which are associated with heritable traits.

Of the 13 sites known to influence the timing of bud burst in oak, and 10 in chestnut, 9 are found to match. But for other traits, including one that helps to govern drought tolerance, the two tree species do not have any QTL in common, showing where they have faced different selection pressures.

\section{CELL BIOLOGY}

\section{Centre of attention}

\section{Science 311,388-391(2006)}

Chromosomes play an active role in positioning themselves centrally during cell division, say researchers.

The replicated DNA molecules within each chromosome are pulled apart during cell division by two sets of molecular fibres that extend from opposite ends of the cell. This happens in two stages, with the fibres from one side attaching first, and dragging the chromosomes to their side of the cell. It was unclear how the second set of fibres could then locate the chromosomes on the far side of the cell. But it turns out they don't have to.

Alexey Khodjakov of the Wadsworth Center in Albany, New York, and his colleagues show that mammalian chromosomes make themselves easier to find. With the help of a motor protein known as CENP-E (kinesin-7), they travel along the fibres of already centred chromosomes rather like using a hand car to travel along a railroad - to reach the middle of the cell.

\section{JOURNAL CLUB}

\section{Mary Schweitzer North Carolina State University, Raleigh}

As new fossil evidence is uncovered, old prejudices fly out of the window, says a palaeontologist.

When the debate over the value of molecular versus morphological data in elucidating evolutionary relationshipswas in its infancy, one of my colleagues published molecular evidence suggesting that modern birds had emergedduring the era of the dinosaurs - much earlier than fossil evidence suggested (B. Hedges et al Nature 381, 226-229; 1996).

Shortly thereafter, I attended a meeting of palaeontologists at which the paper and its implications were disputed, loudly. I overheard one delegate suggest, with annoyance, that molecular people should stick to living organisms, and leave the discerning of early evolutionary patterns to those who study fossils. Moleculardata, from the palaeontologist's point of view, is fine if itagrees with the fossil evidence. But there has been resistance when it contradicts conventional views.

As one who dabbles in palaeontology and molecular biology, I was happy to see a small fossil reconcile the approaches in the debate over birds.

Julia Clarke of North Carolina State University and her colleagues recently analysed the fossil remains of anAntarctic bird dating to the Late Cretaceous period, around 70 million years ago ( $\mathrm{J}$. Clarke et al.
Nature 433,305-308; 2005). They identify the bird as a new species, Vegavis iaai, which belongsto a lineage that includes today's ducks.

The bird shows specialized traits, suggesting thatits lineage diverged long before this specimen lived, and well before the extinction of the dinosaurs, consistent with Hedges' hypothesis. The fossil provides independentevidence to support the molecular data, and acts as a stunning reminder that we mustbe prepared to re-examine our conventional wisdom in the light of new data. 